\title{
La prensa española ante la designación de Adolfo Suárez como presidente del Gobierno en julio de 1976
}

\section{Ricardo Zugasti}

Profesor de Historia del Periodismo Español.

Universidad de Navarra

Resumen:

El presente artículo analiza a través de un análisis de contenido cualitativo la cobertura que la prensa diaria española ofreció acerca de uno de los acontecimientos más trascendentales durante la transición a la democracia: el nombramiento por Juan Carlos I de Adolfo Suárez como presidente del Gobierno, el 3 de julio de 1976. El objetivo es aproximarse al papel jugado por la prensa española durante aquellos años en los que la vista estaba puesta en la liberalización política, así como conocer algo más sobre algunos de los principales protagonistas de aquella etapa histórica.

Palabras clave:

Historia de la prensa - Transición española - Monarquía de Juan Carlos I - Adolfo Suárez.

Abstract:

Through a qualitative content analysis of the Spanish newspaper articles written on the subject at the time, this article examines the press coverage of one of the most decisive events happened during the transition from francoist dictatorship to democracy: the appointment of Adolfo Suárez as Prime Minister on $3^{\text {rd }}$ July 1976, a decision taken by King Juan Carlos I. The aim is to approach the role of the Spanish Press during these years in which efforts were made to democratize, as well as to know more about political personalities who played a leading role at that time.

Key words:

History of the Press - Spanish Transition - King Juan Carlos I - Adolfo Suárez. 


\section{Introducción}

Uno de los acontecimientos más decisivos de la transición española a la democracia fue la designación de Adolfo Suárez por Juan Carlos I para que presidiera el Gobierno de la nación. El mantenimiento de Carlos Arias Navarro al frente del Ejecutivo, reafirmado en su puesto por el Rey tras la muerte de Franco, se había revelado ineficaz en la consecución de una reforma del sistema político; a ello se sumó un rosario de desencuentros personales y políticos entre Don Juan Carlos y el presidente: su sustitución, por lo tanto, se fue mostrando como inevitable (Cfr. Tusell y Queipo de Llano, 2003). Don Juan Carlos citó a Carlos Arias el 1 de julio para forzar su dimisión. Al parecer, el todavía presidente del Gobierno, ante las primeras palabras del Monarca, presentó la dimisión inmediatamente y sin ofrecer resistencia, facilitando al Rey lo incómodo del trámite'.

Conviene recordar que, entre su proclamación en 1975 y la entrada en vigor de la Constitución de 1978, Juan Carlos I ostentó un considerable cúmulo de poder político heredado de la legislación franquista entonces vigente que ponía en sus manos, entre otras muchas atribuciones, la capacidad de nombrar presidente del Gobierno de entre una terna propuesta por el Consejo del Reino (Cfr. Ferrando Badía, 1975). Recaía, por consiguiente, la responsabilidad del nombramiento en el joven Monarca, pues él debía señalar el nombre del presidente. Además, era obvio que la decisión del Consejo del Reino con respecto a los tres candidatos estaba poderosamente influida por la autoridad regia a través del presidente de esta institución y fiel servidor del Rey, Torcuato Fernández-Miranda, nombrado meses atrás por Don Juan Carlos para este cargo.

El día siguiente a la dimisión de Arias, Torcuato Fernández-Miranda consiguió que el Consejo del Reino incluyera el nombre del hasta entonces ministro Secretario General del Movimiento, Adolfo Suárez -el candidato que querían tanto el Rey como su antiguo profesor para sustituir a Arias y sacar adelante la reforma-, en la terna que debía presentar a Don Juan Carlos². Dos días después, el 3 de julio, Adolfo Suárez fue elegido por Juan Carlos I nuevo presidente del Gobierno, lo que supuso una sorpresa, e incluso una decepción, para la opinión pública, que veía con más posibilidades y mejores ojos a los pesos pesados reformistas del anterior Gabinete como Manuel Fraga o, sobre todo, José María de Areilza. Don Juan Carlos ha contado por qué optó por Suárez:

Porque era un hombre joven y moderno. Porque procedía del franquismo y porque no se le podía hacer sospechoso de pretender cambios demasiado radicales, inaceptables para ciertos sectores de nuestra sociedad.

\footnotetext{
${ }^{1}$ La versión que Fraga ofrece en sus memorias de las palabras de Arias ante los miembros del Gobierno es la siguiente: "Arias nos informó lacónicamente de que el Rey le había pedido su renuncia y que se la había ofrecido" (1987, p. 52).

${ }^{2}$ La trayectoria política de Adolfo Suárez y sus vinculaciones anteriores con Don Juan Carlos, que forjaron una corriente de simpatía mutua están, por ejemplo, en Abella (1997).
} 
[...] era joven, moderno y suficientemente ambicioso como para desear ser el hombre capaz de afrontar los momentos que vivíamos (Vilallonga, 1993, p. 99) ${ }^{3}$.

Tras la decisión de Don Juan Carlos, la composición del Gobierno Suárez se conoció el 7 de julio y destacó por la juventud de sus ministros y por la ausencia de grandes figuras políticas, si bien todos sobresalían por su fidelidad a Juan Carlos I y por su unidad de criterios para conseguir el cambio político. El Rey participó activamente en la elaboración del Gobierno, pidiendo incluso personalmente a algunos candidatos que aceptaran el Ministerio. Resultó un equipo con preponderancia de reformistas democristianos como, por ejemplo, Marcelino Oreja en Asuntos Exteriores, Alfonso Osorio en la Vicepresidencia para Asuntos Políticos y Landelino Lavilla en Justicia. También tuvieron peso los reformistas procedentes del Movimiento como Rodolfo Martín Villa, en Gobernación, o Fernando Abril, en Agricultura. Se mantuvieron, a petición del Rey, los ministros militares del anterior Gabinete para dar sensación de estabilidad en el seno del Ejército ${ }^{4}$. Relevantes miembros del anterior Gobierno, entre los que destacaron Fraga (Cfr. 1987) y Areilza (Cfr. 1983), se negaron a continuar como ministros en el nuevo, en parte por considerarlo incapaz de llevar a buen puerto la reforma, y en parte también dolidos al no haber sido ellos los elegidos para presidirlo.

Evidentemente, el nombre del nuevo presidente y su Gobierno aparecían muy unidos al Rey, pues era él quien había elegido a Adolfo Suárez. Esta vinculación se hizo más explícita el 9 de julio, cuando Juan Carlos I presidió el primer Consejo de Ministros del Gobierno Suárez, en un intento por arropar la inicial mala imagen del Gabinete. Al presidirlo, "estaba ligando su prestigio al éxito o el fracaso de Suárez” (Preston, 2003, p. 397). En el discurso que dirigió a los nuevos ministros, el Rey les animó a "hacer posible la participación clara y en paz de todos los ciudadanos en la determinación de nuestro futuro". Fue además rotundo en una breve consigna que quiso dar al Gobierno: "Obrad sin miedo" .

Pese a la importancia histórica de la designación, no se había abordado todavía el estudio del tratamiento periodístico concedido a este acontecimiento, una carencia agravada por el hecho de que se ha convertido en un tópico hablar de la mala recepción que tuvo en la prensa el nombramiento de Suárez. Por todo ello, este artículo tiene como objetivo analizar la cobertura informativa de los diarios españoles ante el evento. El trabajo servirá para arrojar algo más de luz sobre un decisivo momento de la transición y sobre sus protagonistas -especialmente Juan Carlos I y Adolfo Suárez-, así como para aproximarnos al papel jugado por la prensa en su conjunto durante aquellos años y caracterizar cada una de las cabeceras estudiadas.

\footnotetext{
${ }^{3}$ El proceso de elección de Suárez y los porqués de ésta se pueden encontrar, entre otros, en Palacio Atard (1988), Powell (1991), Preston (2003).

${ }^{4}$ Sobre la formación del Gobierno Suárez, veánse Bardavío (1978) y Osorio (2000).

${ }^{5}$ Tomado de $Y a, 10-$ VII-1976, p. 5.
} 
A través de un análisis de contenido de corte cualitativo, se analizaron los siguientes hechos: el nombramiento de Suárez, la formación de su primer Gobierno y la celebración del primer Consejo de Ministros. Los diarios tomados como fuentes fueron los madrileños $A B C$, Informaciones, Ya, El Alcázar, Pueblo y El País; los barceloneses La Vanguardia, Mundo Diario y Avui; el vasco El Correo Español; y finalmente Diario de Navarra. Seleccionamos estas cabeceras atendiendo a tres criterios: la importancia de su circulación, la representatividad de las tendencias políticas y periodísticas existentes en aquellos años, y la cobertura de distintos ámbitos geográficos ${ }^{6}$. Asimismo, se incluyen como fuentes algunos testimonios personales de periodistas con cargos directivos en los rotativos estudiados.

\section{La apuesta de Juan Carlos I}

Juan Carlos I eligió, recordemos, el 3 de julio de 1976, a Adolfo Suárez como presidente del Gobierno. La prensa vinculó mayoritariamente al nuevo presidente con Don Juan Carlos, destacando que era su opción. El Alcázar publicó un artículo de su director, Antonio Gibello, en el que se indicó que Adolfo Suárez había llegado "a tan alta magistratura por decisión de S. M.”. Además de subrayar en su titular que el nuevo presidente era "el primero de la Corona", el artículo afirmó que el Monarca había elegido "a aquél que por su juventud y su talante" estaba "más cerca de su comprensión de los asuntos públicos"7. También para $A B C$, Suárez iba a presidir "el primer Gobierno de la Monarquía”, dando a entender la ineficacia del anterior para actuar conforme a los deseos del Rey; ahora bien, este diario remarcó que el presidente designado había actuado en su anterior etapa como ministro a favor "del avance hacia la democracia, interpretando con clara lealtad la finalidad de la Monarquía y los propósitos de la Corona". Más adelante destacó la fidelidad de Suárez hacia el Rey y hacia las intenciones políticas de éste:

Si a la tradición monárquica del nuevo presidente no deben buscársele antecedentes antiguos porque se rebasarían límites inevitables por su juventud, no hay reparo alguno que oponer, en cambio, a su coherencia con la teoría política de la Corona. Ni tampoco, aunque no sea factor fundamental para esta cuenta, a su personal adhesión a Su Majestad Don Juan Carlos ${ }^{8}$.

Pueblo subrayó, de forma similar a como hizo $A B C$, que Adolfo Suárez venía a ser "si no cronológicamente, sí políticamente el primer Presidente del Gobierno de la Monarquía", cuyo Rey estaba "claramente inclinado hacia las fórmulas democráticas de una sociedad adulta"9. La misma opinión, ampliada, expresó Negrín en el vespertino sindical:

\footnotetext{
${ }^{6}$ Acerca de la prensa durante la transición, véanse, por ejemplo, Alférez (1986), Barrera (1995), Barrera y Zugasti (2001). El Alcázar, 5-VII-1976, p. 2: "El primero de la Corona” (artículo de opinión de Antonio Gibello).

${ }^{8}$ ABC, 4-VII-1976, p. 3: "El nuevo presidente de Gobierno" (editorial).

${ }^{9}$ Pueblo, 5-VII-1976, p. 3: "Un presidente para la democracia” (editorial).
} 
En sentido riguroso, Adolfo Suárez va a presidir el primer Gobierno de la Monarquía, el primer Gobierno del tiempo nuevo. En algún sentido, y si se nos entendiera por lo derecho, podría hablarse de un Ejecutivo, ya que no constituyente, al menos para constituir los condicionamientos necesarios para hacer operante y operativa una plena democracia. Si las cosas discurrieran (y en ellos confiamos) por esta senda, el consenso del país no le iba a faltar. En este orden, los pronunciamientos del Rey han sido claros y, desde luego, acogidos con fervor popular. El nuevo presidente, como es lógico, ejecutará la política real ${ }^{10}$.

De igual forma, Luis Apostua escribió en Ya y en El Correo Español que Adolfo Suárez era "el verdadero primer presidente de S. M. don Juan Carlos”, y que su nombramiento constituyó "una victoria de los reformistas prudentes" "11. Enrique Santín insistió en el mismo diario en que sólo al nuevo Ejecutivo le correspondía “en puridad, el título y la responsabilidad de ser el primer Gobierno del Rey”. Y explicó los motivos:

Y ello por dos fundamentales razones: la primera, por haber sido el actual jefe del Gobierno el primero expresamente elegido por el Monarca de entre la terna que le propuso el Consejo del Reino, y la segunda, por advertirse, en principio, una mayor afinidad entre el pensamiento político del nuevo presidente y el propósito del Soberano de llevar a cabo una auténtica reforma en profundidad que nos asegure una democracia fuerte y estable, en la que el pluralismo político, respetuoso con la legalidad, permita a la voluntad popular expresar libremente sus legítimas opciones y alternativas de poder ${ }^{12}$.

La Vanguardia, por su parte, afirmó que el Monarca había escogido a la persona "más adecuada a sus propósitos", que no eran otros que los de "llevar adelante la política de reformas"13. El también catalán Mundo Diario expresó la repetida idea de que a Suárez se le podía denominar "como auténtico primer presidente del Gobierno de la Monarquía", del que se esperaba que su política contuviera "la necesaria coherencia y agilidad" para cumplir en el plazo más breve posible los reiterados y públicos propósitos de Juan Carlos I sobre una democratización auténtica"14. Pedro Calvo Hernando destacó en Mundo Diario y en Diario de Navarra que Adolfo Suárez era un político "muy estimado en La Zarzuela"'15, buscando así la vinculación con el Rey. El Correo Español afirmó que era el presidente elegido para hacer la transición:

La decisión de la Corona pone, en efecto, en manos de un hombre joven y tenaz la hermosa responsabilidad de conducir la transición [...].

${ }^{10}$ Pueblo, 5-VII-1976, p. 3: “Notas del día” (columna de Negrín).

${ }^{11}$ Ya, 5-VII-1976, p. 16: "Suárez gana la etapa” (columna de Luis Apostua); El Correo Español, 4-VII-1976, p. 23: “Suárez gana la etapa" (columna de Luis Apostua).

${ }^{12}$ Ya, 6-VII-1976, p. 7: "El primer Gobierno del Rey” (artículo de opinión de Enrique Santín).

${ }^{13}$ La Vanguardia, 4-VII-1976, p. 3: "El alcance de un cambio" (editorial).

${ }^{14}$ Mundo Diario, 4-VII-1976, p. 3: "Un presidente para el cambio" (editorial).

${ }_{15}$ Mundo Diario, 4-VII-1976, p. 8: "El joven presidente Suárez” (crónica de Pedro Calvo Hernando); Diario de Navarra, 4-VII1976, p. 4: "Análisis político tras el nombramiento del nuevo presidente” (crónica de Pedro Calvo Hernando). 
[...] su línea de actuación [de Suárez] futura apunta, evidentemente, hacia la aceleración de la reforma, de modo que plasme en realidades vivas y sentidas la expresa y firme voluntad de la Corona en orden a alcanzar una democracia moderna y auténtica para España ${ }^{16}$.

La reacción de El Correo Español ante la designación de Suárez, en consonancia con el anterior editorial, fue la que expresa Antonio Guerrero, subdirector al producirse el hecho: "El nombramiento de Suárez nos cogió a todos por sorpresa. En la 'terna' figuraban nombres más brillantes y menos vinculados al Movimiento. Pero era una de las primeras decisiones del Rey -la más importante, quizá- y la respetamos. Se abrió un ancho margen de confianza a Adolfo Suárez. Esperar y ver"17.

Lorenzo López Sancho, de $A B C$, fue mucho más allá en la identificación entre el Monarca y su nuevo presidente al afirmar que Adolfo Suárez había sido el elegido incluso antes de la presentación de la terna por el Consejo del Reino, tal y como realmente sucedió. Evidentemente, se reforzó la imagen de Don Juan Carlos como actor político:

"Estoy en condiciones de poder ofrecer al Rey lo que me había pedido", cuentan los informadores políticos que declaró el señor Fernández-Miranda al concluir la deliberación del Consejo del Reino. Frase levemente, intencionalmente sibilina. No enunciaba el simple cumplimiento formal de lo que la ley dispone: producir una terna de nombres presidenciables. El Rey no tenía que pedirle una terna al presidente del Consejo del Reino. Era este organismo el que, preceptivamente, debía promoverla. Luego si el Rey no había tenido que pedir una terna, otra cosa habría pedido, y el presidente del alto organismo estaba en condiciones de ofrecérsela.

Es casi imposible no pensar que el nombre del nuevo presidente del Gobierno estaba en la mente del Monarca antes de que el Consejo se reuniera. Y si no era así, la innegable intencionalidad de la frase del señor Fernández-Miranda era una simple ligereza de construcción verbal, lo que en un hombre de la fina calidad intelectual del presidente de las Cortes es absolutamente impensable. [...]

De no ser la cosa así, y no tiene por qué no haberlo sido, ya que el Monarca tenía que salir del "impasse" en que las cosas demasiado "atadas y bien atadas" colocaban peligrosamente a la Corona, lo que ayer decíamos se confirmaría: el Consejo del Reino ha cumplido un cometido meramente ritual, santificante, legitimizante de una decisión del Monarca. De una decisión que era ya imperiosamente necesaria ${ }^{18}$.

Juan Luis de Simón Tobalina mostró en $\mathrm{Ya}$ la misma opinión que López Sancho, tomando asimismo como base de su interpretación las palabras de Torcuato Fernández-Miranda:

Hay, sin embargo, en la referencia de prensa de la tramitación de este nombramiento una frase salida -entre sonrisas y amabilidades- de los labios del presidente del Consejo del Reino que ha suscitado numerosos comentarios. Esta: "Estoy en condiciones de ofrecer al Rey lo que me ha pedido". ¿ Ha habido en la designación

\footnotetext{
${ }^{16}$ El Correo Español, 4-VII-1976, p. 23: "Un nuevo horizonte” (editorial).

${ }^{17}$ Testimonio por escrito de Antonio Guerrero al autor. Bilbao, 22-IV-2004. Además de Adolfo Suárez, en la terna figuraron Federico Silva y Gregorio López Bravo.

${ }^{18}$ ABC, 6-VII-1976, p. 6: “Una operación política” (columna de Lorenzo López Sancho).
} 
del señor Suárez un 'impulso soberano'? [...] Esta versión optimista, a la que deseo asirme, implica que el Rey ha dado un paso valiente: el de hacerse más responsable -dentro de su irresponsabilidad jurídica constitucional- de la futura marcha de los acontecimientos ${ }^{19}$.

Pedro Calvo Hernando compartió la creencia de la implicación regia en el nombramiento: "Parece confirmarse que la operación de nombramiento de Suárez ha sido promovida por el Rey, con el eficaz apoyo de Fernández-Miranda" ${ }^{20}$.

Buena parte de los comentarios vistos hasta aquí pusieron énfasis en que el nuevo presidente debía hacer posible la voluntad democratizadora del Rey. Una vez más, la nota discordante fue El Alcázar, que publicó dos artículos en los que consideró que la adopción de medidas para paliar la crisis económica tenía preferencia sobre la reforma política. Antonio Gibello, director del periódico, lo expuso con las siguientes palabras:

Sin despreciar los de linaje político que afectan a la convivencia nacional y a la concepción misma de la Patria, entiendo que la crisis de confianza del pueblo en el Gobierno radica en la incapacidad para solucionar los problemas económicos que son desencadenantes de la espiral de conflictividad social y que acentúan el torbellino del desorden político general ${ }^{21}$.

\section{Gobierno:}

Más tajante se mostró Ismael Medina, en lo que fue una cruda advertencia al nuevo presidente del

En efecto, si [Adolfo Suárez] quiere asegurar al pueblo lo que al pueblo le interesa, es decir, la restauración de la salud socioeconómica, habrá de considerar secundaria la reforma política y ralentizarla, haciendo frente a la iracundia y a la demagogia de la oposición. Pero si se siente obligado a mantener la aceleración reformista y halagar a la oposición interior y exterior, la quiebra económica y sus resultantes sociales le arrastrarán, haciéndole sentir como lanzas los halagos de hoy ${ }^{22}$.

La identificación entre el Rey y su presidente se puso también de manifiesto a través de los comentarios de la prensa extranjera recogidos por los diarios españoles. Los artículos europeos y norteamericanos -de donde fundamentalmente procedía la prensa citada por los periódicos españoles- indicaron la amistad y la buena sintonía existentes entre Don Juan Carlos y Adolfo Suárez, además de la lealtad y adhesión de este último hacia su Monarca ${ }^{23}$.

${ }^{19} Y a, 6$-VII-1976, p. 7: "El Gobierno que se espera” (artículo de opinión de Juan Luis de Simón Tobalina).

${ }^{20}$ Mundo Diario, 4-VII-1976, pp. 1 y 2: “Un hombre del Rey” (crónica de Pedro Calvo Hernando).

${ }^{21}$ El Alcázar, 5-VII-1976, p. 2: "El primero de la Corona” (artículo de opinión de Antonio Gibello).

${ }^{22}$ El Alcázar, 5-VII-1976, p. 2: “Adolfo Suárez, entre la España declamatoria y la España que se hunde” (columna de Ismael Medina).

${ }^{23}$ Cfr. El Alcázar, 5-VII-1976, p. 11: “Según 'Washington Post'. Un liderazgo fuerte” (crónica sin firma); ABC, 6-VII-1976, p. 21: " $A B C$ en Nueva York: Adolfo Suárez, firme partidario de la Monarquía” (crónica de A. Marín); ABC, 7-VII-1976, p. 21: “"El Rey tiene ahora un amigo como primer ministro”" (crónica de Efe); Pueblo, 5-VII-1976, p. 9: "Ecos en el extranjero” (crónica de José 
Una característica de Suárez muy comentada por la prensa fue su juventud, ya que contaba 43 años cuando fue nombrado presidente del Gobierno. Esta edad le aproximaba "generacionalmente al Rey"24, como comentó El País, ya que ambos pertenecían a la generación que no hizo la Guerra Civil. Antonio Gibello destacó en El Alcázar este rasgo como motivo de esperanza: “¿Acaso no se insiste frecuentemente en que dos tercios de la población española no hicieron la guerra? Pues ya está, al frente de los destinos del gobierno, un hombre joven que no hizo la guerra" ${ }^{25}$. $A B C$ resaltó asimismo este atributo de Suárez:

La opción real ha sido, a lo que cabe juzgar en estos primeros momentos, una decisión a favor de la joven política, de la política que muy bien puede simbolizar, con experiencia suficiente en el servicio a los más altos intereses nacionales y comunitarios pero sin excesiva carga cronológica, Adolfo Suárez.

Y desde este punto de vista quizá esté cargada de significación histórica y de favorable presagio una elección que recae en personalidad política ajena a la dramática conflictividad civil anterior a la guerra del 36, y ajena, también, al desarrollo sangriento y a las consecuencias inmediatas de la propia guerra ${ }^{26}$.

Con igual intención, Pueblo puso de relieve que el nuevo presidente no había conocido "el enfrentamiento entre españoles -tenía sólo cuatro años al dar comienzo nuestra guerra civil-, pero sí la realidad de una postguerra erizada de gravísimas dificultades materiales" ${ }^{27}$. Un comentario similar, aunque más extenso y con una interpretación política más profunda, encontró cabida en las páginas de Mundo Diario:

Es de observar cómo la complicada y difícil situación política y económica que atraviesa España queda ahora, con el superior arbitraje de un Monarca joven, bajo la directa responsabilidad de un jefe de Gobierno que cabe situar en la propia generación del Rey. El dato es significativo por cuanto a las dotes políticas de Adolfo Suárez, hay que acumular su escasa vinculación a un pasado que el país demanda dejar en la historia para caminar resueltamente hacia un futuro de plena democracia. Adolfo Suárez entra en ese enorme $75 \%$ de españoles que no conocieron la guerra civil, o cuando menos sólo la entrevieron en su infancia. Su designación tiene mucho de simbolismo del buque que suelta amarras y se lanza a una nueva, apasionante singladura. Sin nostalgias estériles $^{28}$.

María Carrascal ); Ya, 5-VII-1976, p. 11: “Sorpresa en los ambientes europeos ante el nombramiento de don Adolfo Suárez” (crónica de Joaquín Portillo); Informaciones, 6-VII-1976, p. 3: "El 'New York Times' dice que 'el Rey tiene ahora a un amigo como primer ministro"” (crónica de Efe); La Vanguardia, 6-VII-1976, p. 6: “Bélgica: 'Fiel ejecutor de las decisiones del Soberano”” (crónica de Efe); Mundo Diario, 4-VII-1976, p. 32: "Bélgica: 'Joven falangista”" (crónica de Efe); El Correo Español, 4-VII-1976, p. 32: "Sorpresa en la OTAN y la CEE” (crónica de Joaquín Prieto); Diario de Navarra, 6-VII-1976, p. 7: "El presidente Suárez en la prensa francesa” (crónica de Efe).

${ }^{24}$ El País, 4-VII-1976, p. 1: “Adolfo Suárez, nuevo presidente del Gobierno” (crónica sin firma).

${ }^{25}$ El Alcázar, 5-VII-1976, p. 2: "El primero de la Corona” (artículo de opinión de Antonio Gibello).

${ }^{26}$ ABC, 4-VII-1976, p. 3: "El nuevo presidente de Gobierno" (editorial).

${ }^{27}$ Pueblo, 5-VII-1976, p. 3: "Un presidente para la democracia” (editorial).

${ }^{28}$ Mundo Diario, 4-VII-1976, p. 3: "Un presidente para el cambio" (editorial). 
Un artículo de Alfonso Paso en El Alcázar también hizo referencia a que Suárez no vivió la contienda, si bien destilaba cierta crítica hacia aquellos comentarios que hicieron especial hincapié en este hecho, ya que para este columnista lo importante era que Suárez había vivido la paz del franquismo:

Más he aquí que otros menos listos y más sutiles afirman que lo que se pretendía prefiriendo a Adolfo Suárez, era que el Gobierno estuviese encabezado por un hombre joven, que no hubiera hecho la guerra. De este modo se alejaba lo que algunos malévolos llaman 'el fantasma de la contienda' y se abría paso a la juventud. [...] Pero el Presidente del Gobierno ha tenido una experiencia vital mucho más importante y más densa: vivió la paz. Es decir, supo lo que fue la paz de Franco ${ }^{29}$.

Cuando el 8 de julio se hizo pública por la prensa la composición del nuevo Gabinete, los comentarios periodísticos -también aquéllos que reproducían artículos de la prensa extranjera ${ }^{30}$ - volvieron a resaltar la juventud, ésta vez la de buena parte de los ministros, uniéndola a la del Rey y Suárez. Luis Apostua sostuvo en $Y a$ que se había producido "el barrido, quizá definitivo, de los santones de la política en los últimos treinta años", lo que significaba "un corte generacional [...] con la generación de la guerra". Eso sí, terminó su artículo afirmando la necesidad de que los jóvenes ministros demostraran que eran jóvenes ${ }^{31}$. Pueblo dijo que "la juventud era la tónica casi general en el equipo de Adolfo Suárez" ${ }^{32}$; de la "notable juventud" 33 y de "la constante de la juventud" ${ }^{34}$ hablaron respectivamente El País y La Vanguardia. “Un Gobierno joven”35, así lo calificó, como rasgo principal, El Correo Español.

La celebración el 9 de julio del primer Consejo de Ministros del nuevo Ejecutivo, bajo la presidencia del Rey, volvió a provocar en la prensa una avalancha de comentarios sobre la juventud de algunos ministros y su identificación con el Jefe del Estado por pertenecer a la misma generación. El propio Monarca aludió a ello diciendo que el nombramiento de los ministros presentes representaba "la llegada de una nueva generación a las responsabilidades del Consejo de Ministros"36. Para $A B C$, esta juventud suponía mayor facilidad a la hora de buscar el diálogo:

Ha sido precisamente este dato generacional, aplicado a los ministros nuevos, la base sobre la que se abre mayor margen de confianza a la política que se proponga realizar el Gabinete presidido por Adolfo Suárez. Ya

${ }^{29}$ El Alcázar, 7-VII-1976, p. 3: “Dos acontecimientos” (columna de Alfonso Paso).

${ }^{30}$ Cfr., por ejemplo, Ya, 8-VII-1976, p. 11: “El nuevo gobierno, calificado de tendencia liberal y de centro derecha” (crónica de Gustavo Valverde); Pueblo, 10-VII-1976, p. 6: "Legalización de los partidos y pacto social” (crónica de Efe); Informaciones, 9VII-1976, p. 4: "París: un gobierno entre dos luces” (crónica de Rafael Conte); El Correo Español, 9-VII-1976, p. 23: "Gran Bretaña: se destaca la juventud del Gabinete" (crónica de Luis Irazu).

31 Ya, 9-VII-1976, p. 17: "Hechos sociológicos" (columna de Luis Apostua).

32 Pueblo, 8-VII-1976, p. 3: "Un equipo se pone en marcha” (editorial).

33 El País, 8-VII-1976, p. 1: "Un análisis del nuevo Gabinete" (editorial).

${ }^{34}$ La Vanguardia, 8-VII-1976, p. 3: "Un gobierno gestor" (editorial).

${ }^{35}$ El Correo Español, 9-VII-1976, p. 22: "La reforma sigue” (editorial).

${ }^{36}$ Tomado de $A B C, 10-$ VII-1976, p. 1. 
en anterior comentario subrayamos que son los ministros, en su mayoría, hombres hechos en la postguerra, con historial no condicionado por decisivos compromisos respectivos. Esta circunstancia permite esperar que el equipo ministerial tenga y ejercite gran capacidad de diálogo ${ }^{37}$.

Pueblo también destacó que el Ejecutivo fuera "tan próximo generacionalmente al nuevo soberano", que aún no había cumplido "los treinta y nueve años"38. En el mismo diario, Negrín aplaudió la "arribada generacional", ya que a dicha generación le reconocía el deseo de "preparar el camino para la democracia, en paz y en orden, pero también con urgencia" ${ }^{39}$. La Vanguardia vio en el hecho de que entre el Rey y el Gobierno no hubiese diferencias de edad un factor influyente para su buen entendimiento, “en singulares términos de confianza" ${ }^{40}$. Una crónica de De Pablo en Ya apuntó a que la oposición tomara nota y renovara a sus líderes como había hecho el Monarca, pues así podía haber "posibilidad de llegar a una mejor comunicación entre las nuevas generaciones", militaran "en el poder o en la oposición" ${ }^{41}$. Sobre la misma característica opinó Pedro Calvo Hernando en Mundo Diario. Según su testimonio, el nombramiento de Suárez constituyó en su caso "cierta sorpresa", aunque reconoce que el conocimiento personal que tenía de él, al que consideraba "políticamente hábil”, y su juventud, le inclinaron a no valorarlo negativamente ${ }^{42}$ :

En el discurso del Rey ante el Gobierno, en el Consejo de Ministros celebrado ayer en La Zarzuela, hay una clave de alto interés político. El Rey ha venido a decir que el poder ha sido puesto en manos de una nueva generación, licenciando a los bonzos del sistema. No sé dónde oí anoche el comentario de que si la oposición democrática hiciera lo mismo con sus bonzos, el entendimiento, el pacto democrático se facilitaría enormemente. Claro que ésa era una opinión muy particular. La ventaja es que esa nueva generación de hombres del sistema y de la oposición no se ha peleado nunca ni ha participado en la guerra civil ${ }^{43}$.

\section{Una designación acogida con sorpresa y desconfianza}

Podemos afirmar que el nombramiento de Adolfo Suárez como presidente del Gobierno fue recibido favorablemente por buena parte de la prensa, y lo visto hasta aquí da muestra de ello. Ahora bien, hubo diarios que publicaron artículos donde se plasmó sorpresa y recelo ante la designación por considerar que el nuevo presidente no tenía el suficiente peso político ni el suficiente talante democrático para emprender la reforma. Paradigmático de ese recelo despertado fue, por ambiguo, un comentario de $L a$

${ }^{37} A B C, 10-\mathrm{VII}-1976$, p. 3: "Llegada de una nueva generación" (editorial).

${ }^{38}$ Pueblo, 10-VII-1976, p. 3: "Hacer posible lo que es necesario" (editorial).

${ }^{39}$ Pueblo, 10-VII-1976, p. 3: "Notas del día” (columna de Negrín).

40 La Vanguardia, 10-VII-1976, p. 3: "La mirada de un pueblo" (editorial).

${ }^{41} \mathrm{Ya}$, 12-VII-1976, p. 14: "Es propósito del gobierno acelerar en lo posible la reforma” (crónica de F. L. de Pablo).

${ }^{42}$ Entrevista del autor con Pedro Calvo Hernando. Madrid, 21-I-2004.

${ }^{43}$ Mundo Diario, 10-VII-1976, p. 5: “Amnistía para delitos estrictamente políticos” (crónica de Pedro Calvo Hernando). 
Vanguardia: "Es posible que se trate de un buen cambio; es probable que no se trate de un gran cambio" 44 . Jaume Arias, entonces subdirector del diario barcelonés, admite que mostraron "recelo al principio", debido fundamentalmente a que "Suárez carecía de equipo". Sin embargo, "los recelos pronto se disiparon, al ver que formó Gobierno y que comenzaba a actuar bien" ${ }^{\text {. }}$.

El hecho de que fuera un político procedente del Movimiento fue visto por varios periódicos como un lastre. "No podemos desconocerlo: la imagen que de él dan su procedencia política y la misma cartera que ha desempeñado no es la más propicia", escribió $Y a$, aunque matizó acto seguido tal afirmación: "Consta sin embargo, su sincero propósito de llevar adelante el cambio constitucional sin más paralizaciones" ${ }^{46}$. El entonces director del rotativo, Alejandro Fernández Pombo, explica esta reacción de su periódico al afirmar que la elección de Suárez fue "una sorpresa". La principal razón para el posterior y mantenido apoyo de $Y a$ al nuevo presidente se fraguó al conocerse la composición de su Gabinete: "Se dejó ver que nos había sorprendido el nombramiento y mantuvimos una reserva inicial, pero le apoyamos tras conocer su Gobierno, en el que los tácitos estaban muy representados. Y muchos de ellos eran incluso consejeros del $\mathrm{Ya}$. Sabíamos que eran hombres que pensaban en nuestra línea. Salió un equipo que no podía ser más en la línea de $Y a$. Nos pareció muy oportuno" 47 .

Informaciones calificó la designación de "innegable sorpresa" y vio en la trayectoria política del nuevo presidente su principal obstáculo, si bien le otorgó un margen de confianza:

Para el señor Suárez, su historial político, siempre directamente ligado al Movimiento, cuya Secretaría General ha ocupado durante los seis últimos meses, no supone un punto de partida favorable en esa tarea de establecer puentes de comunicación con una oposición que se muestra hoy recelosa. [...]

Por otra parte, no faltan los indicios de que la figura del señor Suárez puede ir más allá de esos condicionamientos aparentes, de que puede superar las dificultades y completar esa ardua tarea ${ }^{48}$.

Los recuerdos de Jesús de la Serna, director de Informaciones durante la transición, referidos a cómo su diario acogió el nombramiento coinciden con la opinión mostrada en el editorial visto, con esa mezcla de sorpresa y esperanza: "Me sorprendió el nombramiento; en el caso de Informaciones cabe hablar más de sorpresa que de decepción. La decisión desorientó porque Suárez no era un peso pesado de la política y su cargo había sido el de cabeza visible del Movimiento. Sin embargo, el Rey conocía bien a Suárez, eran amigos y ese trato, a mí, que conocía las intenciones políticas de Don Juan Carlos, me hizo ver que las cosas iban a cambiar" 49 .

${ }^{44}$ La Vanguardia, 4-VII-1976, p. 3: "El alcance de un cambio" (editorial).

${ }^{45}$ Entrevista del autor con Jaume Arias. Barcelona, 11-II-2004.

${ }^{46} \mathrm{Ya}, 5$-VII-1976, p. 7: "Nuevo presidente" (editorial).

${ }^{47}$ Entrevista del autor con Alejandro Fernández Pombo. Madrid, 31-X-2003. La firma colectiva “Tácito” publicó en Ya entre 1973 y 1975, y estaba formada por jóvenes políticos de talante democristiano, defensores del tránsito a la democracia desde el franquismo (Cfr. Powell, 1990).

${ }^{48}$ Informaciones, 5-VII-1976, p. 18: "La difícil tarea del presidente" (editorial).

${ }^{49}$ Entrevista del autor con Jesús de la Serna. Madrid, 28-X-2003. 
Diario de Navarra se mostró decepcionado, pues de los tres nombres de la terna salió "el de más lastre político del viejo régimen". Para el periódico navarro, sin embargo, esto podía tener la ventaja de una mayor facilidad en el tránsito a la democracia si lo conducía un conocedor de los entresijos del Régimen que se hiciera respetar por las "viejas fuerzas" ${ }^{50}$. Uranga, director del Diario en aquel momento, rememora que la decisión "causó una sorpresa y una decepción tremendas porque pensamos que era volver a Falange. [...] Pero no criticamos con dureza porque entonces no estaban las cosas para criticar. Además, se tenía confianza en el Rey y en Torcuato Fernández-Miranda, que habían sido los promotores de Suárez" ${ }^{51}$.

El mismo problema sobre la procedencia del presidente dejó entrever Avui, ya que en una fotografía mostró al nuevo jefe del Gobierno vestido con el uniforme falangista ${ }^{52}$. Además, el titular de portada que dio noticia de la designación decía: "Suárez, del 'Movimiento' a la Presidencia"53. La crítica más dura a la elección provino de El País. En un editorial afirmó que Suárez poseía "las virtudes propias de un buen político", pero que no era aquélla "hora de políticos, sino de estadistas". E incidió en la reprobación del anterior cargo del presidente:

No deben los españoles negar su ayuda al presidente del Gobierno, pero por honradez y por patriotismo es preciso decir a éste que va a necesitar mucha. Hay un amplio consenso de opinión respecto al hecho de que la tarea que le aguarda es mucho mayor que las ilusiones que suscita, sobre todo si se piensa que quien ahora accede a la máxima responsabilidad ejecutiva de la nación lo hace desde la Secretaría General del Movimiento. Dato anecdótico seguramente, pero que aumenta las dificultades a la hora de anunciar una política de reconciliación ${ }^{54}$.

Augusto Delkader, redactor jefe de El País al producirse la designación de Suárez, afirma que "el nombramiento fue bastante sorprendente" y basa la opinión reticente de su diario en que "los antecedentes de Adolfo Suárez no eran el aval más nítido para transformar el Régimen”"55.

Numerosas informaciones basadas en las reacciones de la prensa foránea también pusieron de manifiesto la sorpresa y la decepción que provocó en muchos órganos informativos -fundamentalmente europeos- la designación de Suárez como presidente ${ }^{56}$. Se esperaba un político con mayor "pedigrí"

${ }^{50}$ Diario de Navarra, 4-VII-1976, p. 1: “Los porqués del nuevo Presidente” (editorial).

${ }^{51}$ Entrevista del autor con José Javier Uranga. Pamplona, 28-XI-2003.

${ }^{52}$ Cfr. Avui, 4-VII-1976, p. 11.

${ }^{53}$ Avui, 4-VII-1976, p. 1.

${ }^{54}$ El País, 4-VII-1976, p. 6: "El presidente" (editorial).

${ }^{55}$ Entrevista del autor con Augusto Delkader. Madrid, 12-V-2004.

${ }^{56}$ Cfr., por ejemplo, $A B C$, 4-VII-1976, p. 11: "Sorpresa general ante el nombramiento" (crónica de Pablo Sebastián); Ya, 5-VII1976, p. 11: "Don Adolfo Suárez, presentado como conservador en los medios de difusión alemanes” (crónica de J. V. Colchero); Informaciones, 5-VII-1976, p. 4: "París: sorpresa y desconcierto" (crónica sin firma); El País, 6-VII-1976, p. 10: "Bonn. Paso atrás en las reformas" (crónica de Efe); El País, 7-VII-1976, p. 9: "El gran perdedor, en el plano internacional, es el Rey" (crónica de 
democrático, y en boca de todos estaba el anterior ministro de Asuntos Exteriores, José María de Areilza. Incluso puede afirmarse que el grueso de las críticas a la elección de Suárez fueron comentarios extranjeros recogidos en los diarios españoles.

La composición del primer Gobierno presidido por Suárez provocó también una serie de críticas y reticencias periodísticas. El principal reproche fue que se consideraba a los ministros como políticos de segunda fila, sin experiencia para el cargo que tenían que desempeñar. Esta bisoñez parecía ser la cara negativa de su juventud, tan bien valorada por los diarios. Informaciones subrayó "la ausencia de figuras políticas de primer plano" y que "el relativo anonimato de muchos de sus componentes" contribuía "a alimentar las dudas y las suspicacias" ${ }^{57}$. El País hizo notar como característica apreciable "lo desconocido de la faz política de algunos de ellos [...]. ¿ Y éste quién es? era la pregunta más extendida ayer en las redacciones de los periódicos" "58. Un cronista de Avui puso de manifiesto que no era "un gobierno de primeras espadas, sino de figuras [...] consideradas de segundo o de tercer orden" 59 . Lo mismo hizo El Correo Español al reconocer la imposibilidad de calificarlo como "un plantel de grandes figuras políticas" 60 .

Una severa crítica, no centrada en el poco peso político del Gobierno, fue la que publicó Ricardo de la Cierva en El País bajo el expresivo título de “iQué error, qué inmenso error!”. En dicho artículo, que ha pasado a la historia como ejemplo de las suspicacias ante el nuevo Gobierno, De la Cierva mostró descarnadamente su desilusión por el desarrollo de la crisis, pues consideró que se había constituido un Ejecutivo franquista:

Nada mejor que unas palabras de Franco para titular la crónica sobre el advenimiento del primer Gobierno de Franco en la Monarquía; el primer Gobierno franquista del postfranquismo. Tal expresión no implica la menor connotación peyorativa, impropia en el cronista; es una simple y descarnada descripción. El error consiste, primeramente, en haber designado a un nuevo Gobierno de Franco cuando toda la opinión interior y exterior -ojo, digo opinión política, no simplemente clase política- esperaba, después de la cordial defenestración de don Carlos Arias, la inauguración del primer Gobierno del nuevo régimen. Y en lugar de eso nos hemos topado con un error, un inmenso error.

Feliciano Fidalgo); La Vanguardia, 4-VII-1976, p. 9: “Sorpresa, porque se esperaba un hombre más liberal” (crónica sin firma); Mundo Diario, 6-VII-1976, p. 4: "Sorpresa y decepción” (crónica sin firma); Avui, 6-VII-1976, p. 2: "França. L’elecció de Suárez defrauda" (crónica de Ernest Udina); El Correo Español, 6-VII-1976, p. 24: "La prensa alemana señala la sorpresa del nombramiento" (crónica de Efe); Diario de Navarra, 4-VII-1976, p. 7: "Sorpresa y decepción entre los corresponsales extranjeros de prensa" (crónica sin firma).

${ }^{57}$ Informaciones, 8-VII-1976, p. 18: "Un margen de confianza” (editorial).

${ }^{58}$ El País, 8-VII-1976, p. 1: "Un análisis del nuevo Gabinete” (editorial).

${ }^{59}$ Avui, 8-VII-1976, p. 1: "Ja hi ha nou govern” (crónica de Josep M. Puigjaner).

${ }^{60}$ El Correo Español, 9-VII-1976, p. 22: "La reforma sigue” (editorial). En este mismo diario se publicaron también dos artículos que repitieron igual consideración. Cfr. El Correo Español, 9-VII-1976, p. 21: "A su medida” (artículo de opinión de Armando Fernández-Xesta); El Correo Español, 9-VII-1976, p. 22: “Claves para una crisis” (crónica de Amalia S. Sampedro). 
Esto es un Gobierno de Franco, primero, por lo inesperado y desvinculado de la opinión política; segundo, por la conjunción de fuerzas sociales que articulaban el franquismo; tercero, porque aparenta una fachada diferente del contenido y las raíces; cuarto, porque deja al margen a las fuerzas siempre marginadas; la oposición, las regiones, la media nación femenina ${ }^{61}$.

El diario de Prisa publicó también una página con las crónicas de sus corresponsales en Europa en las que se recogían críticas al nuevo Gobierno publicadas por la prensa extranjera ${ }^{62}$. Por todo ello, El País se caracterizó por ser el diario más agresivo contra el Gobierno Suárez al conocerse su composición.

La reserva de parte de la prensa ante la elección de Suárez y ante la formación de su Gabinete estuvo también presente en la opinión pública española. En mayo de 1976, tan sólo el $29 \%$ de la población consideró que la situación política del país era buena, lo que fue el nivel más bajo desde 1966, primer año del que disponemos datos. La inactividad del Gobierno Arias tuvo, sin duda, reflejo en esta valoración. Ahora bien, la cifra se mantuvo exactamente en julio de 1976, una vez relevado Arias por Suárez. Cuando el nuevo Ejecutivo comenzó a actuar con pasos firmes hacia la democracia, la estima de la situación política empezó a mejorar y, así, en diciembre de 1976, tras la aprobación de la Ley para la Reforma Política, un 52\% valoró positivamente la situación. (Cfr. López Pintor, 1982; Instituto de la Opinión Pública, 1976).

Pese a los comentarios desfavorables, buena parte de la prensa hizo ver que lo realmente importante era que el nuevo Gobierno supiera conducir la reforma política, el principal punto donde encalló el equipo presidido por Arias. "El Gobierno del Rey ha de ser coincidente con las palabras del Soberano, y éstas no dejan lugar a dudas sobre la intención que hoy mueve a la joven España” ${ }^{63}$, escribió Pueblo, dando por seguro que así sería. Este diario no publicó comentarios reticentes ante la designación de Suárez, algo que el entonces redactor político Antonio Casado atribuye al carácter paraestatal del rotativo: "Podemos afirmar que Pueblo hacía seguidismo del Gobierno. Esta característica marcó su postura ante la designación de Suárez. Pese a que la sensación que causó en la redacción fue decepcionante, luego no se publicó nada en este sentido. No podíamos entender cómo iba a facilitar el camino hacia la democracia un señor que venía de Falange" ${ }^{64}$.

Al igual que Pueblo, tampoco $A B C$ ni El Alcázar dejaron entrever su desilusión o descontento. Llamativa es la ausencia del menor reproche en El Alcázar, ya que poco después este diario iba a ser el más crítico con el nuevo presidente y con sus medidas democratizadoras. Quizá ahí esté la clave: $E l$

${ }^{61}$ El País, 8-VII-1976, p. 12: “¡Qué error, qué inmenso error!” (artículo de opinión de Ricardo de la Cierva).

${ }^{62}$ Cfr. El País, 9-VII-1976, p. 10: "París. La operación Suárez puede perpetuar el franquismo” (crónica de Feliciano Fidalgo); El País, 9-VII-1976, p. 10: "Lisboa. Políticos desconocidos que pertenecen al ala conservadora” (crónica de Francisco Velázquez); El País, 9-VII-1976, p. 10: "Londres. Decepción e incertidumbre” (crónica de Juan Cruz).

${ }^{63}$ Pueblo, 8-VII-1976, p. 3: "Un equipo se pone en marcha” (editorial).

${ }^{64}$ Entrevista del autor con Antonio Casado. Madrid, 4-XII-2003. 
Alcázar no recibió mal a alguien procedente del Movimiento y que, como estamos viendo, supuso para algunos un parón en la reforma. Junto a esto, Antonio Gibello relativiza la sorpresa que produjo el nombramiento de Suárez: “En los corrillos políticos se hablaba de sus posibilidades”65. Por su parte, José Luis Cebrián apunta a que, para $A B C$, el nombramiento venía a ser más o menos satisfactorio: "El nombramiento de Suárez no fue tanta sorpresa porque precisamente lo que se buscaba era que fuese una persona del Régimen, pero que fuera joven y que tuviera, por otro lado, unas credenciales por lo menos de deseos democráticos”66.

Informaciones habló de la necesidad de dotar al Ejecutivo de "un margen de confianza", a ver si era capaz de llegar a la meta última, es decir, "las elecciones generales" que diesen "paso finalmente a un Gobierno representativo" 67 . El País no pidió un margen de confianza, aunque sí tenía clara la tarea que correspondía al Gabinete: "La consecución de una democracia real, con la convocatoria de elecciones generales" ${ }^{68}$. La Vanguardia también le advirtió de que, para obtener credibilidad, tenía que "darle al pueblo" lo que le correspondía: la "soberanía"69. La misma idea expresó Mundo Diario: "Si este Gobierno logra [...] que el poder no sea de una minoría, sino reflejo de la realidad social, el Gabinete Suárez habrá prestado al país y a la Monarquía el mejor de los servicios" ${ }^{70}$. A este respecto y de modo coincidente, un subdirector de este diario catalán, Jaume Serrats, afirma que "el nombramiento de Suárez causó sorpresa, pero no una sorpresa demasiado negativa. Y es que habíamos valorado muy positivamente el cambio de Arias"71.

Para Avui, el Gobierno supuso “decepción”, pero no exenta de "esperanza”, pues para el presidente y sus ministros era posible "todavía abrir al país la puerta a la democracia completa"72. El primer director del diario en catalán afirma que aceptaron a Suárez porque vimos que podía "democratizar el sistema": "Era un hombre que procedía del Movimiento, pero un hombre de otra generación"73. De la misma opinión fue El Correo Español; el rotativo vasco cifró el objetivo en alcanzar "esa democracia auténtica, en línea con la expresa voluntad de la Corona y con las exigencias actuales del pueblo español"74.

65 Entrevista del autor con Antonio Gibello. Madrid, 3-XII-2003.

${ }^{66}$ Entrevista del autor con José Luis Cebrián Boné. Madrid, 29-X-2003.

67 Informaciones, 8-VII-1976, p. 18: "Un margen de confianza" (editorial).

68 El País, 8-VII-1976, p. 1: “Un análisis del nuevo Gabinete” (editorial).

${ }^{69}$ La Vanguardia, 8-VII-1976, p. 3: “Un gobierno gestor” (editorial).

${ }^{70}$ Mundo Diario, 8-VII-1976, p. 4: “Lo urgente y necesario” (editorial). Este mismo artículo sugirió comenzar con decisiones claras y concretas como, por ejemplo, la amnistía.

71 Entrevista del autor con Jaume Serrats. Barcelona, 4-II-2004.

72 Avui, 9-VII-1976, p. 1: “Decepció, però...” (editorial). Los requisitos de esta democracia completa eran para Avui la amnistía, el reconocimiento de los derechos sociales y políticos, y la autonomía.

73 Entrevista del autor con Josep Faulí. Barcelona, 3-II-2004.

${ }^{74}$ El Correo Español, 9-VII-1976, p. 22: “La reforma sigue” (editorial). 
El primer Consejo de Ministros se celebró en La Zarzuela, bajo presidencia del Rey. Dicha presidencia y las palabras del Monarca al nuevo Gabinete -entre las que destacó una petición para que obrasen sin miedo- fueron interpretadas como una forma de arroparle y darle aliento ante la tibieza con que fue recibido ${ }^{75}$.

Toda la prensa resaltó en sus titulares las palabras de Don Juan Carlos al Gobierno en esta su primera reunión formal, lo que produjo una mayor identificación entre éste y aquél. Cabe resaltar que fueron El Alcázar y $A B C$ los dos únicos diarios que llevaron a sus titulares la indicación o consejo del Rey para que los ministros hicieran gala de una firme autoridad: "Que éste sea un Gobierno fuerte en un Estado fuerte" ${ }^{76}$. Por su parte, el resto de periódicos reprodujeron en sus titulares todo aquello que en el discurso de Don Juan Carlos apuntó, de una forma más o menos explícita, hacia el establecimiento de un sistema democrático ${ }^{77}$.

\section{A modo de conclusión}

A la luz de lo visto, la designación de Adolfo Suárez como presidente del Gobierno recibió una de cal y otra de arena por parte de los periódicos españoles. La prensa reaccionó en su conjunto con una mezcla de sorpresa y recelo ante el nombre del elegido. Se juzgó negativamente la procedencia falangista de Suárez, así como el cargo de ministro secretario general del Movimiento que había ostentado en el Gabinete Arias, un puesto que parecía restarle crédito democrático. Una vez conocida la composición del primer Gobierno de Suárez, los nuevos ministros fueron considerados como políticos inexpertos y de segunda fila.

Por el contrario, la prensa valoró positivamente la juventud de los miembros del nuevo Ejecutivo, Suárez incluido, que les acercaba a un Rey también joven y les alejaba de experiencias vitales durante la Guerra Civil. Se les otorgaba de esta forma más facilidad para conseguir el consenso olvidando los rencores del pasado y una mayor cercanía generacional con los afanes liberalizadores.

${ }^{75}$ Cfr. ABC, 10-VII-1976, p. 3: “Llegada de una nueva generación” (editorial); La Vanguardia, 10-VII-1976, p. 3: “La mirada de un pueblo" (editorial); Mundo Diario, 10-VII-1976, p. 3: “Obrar sin miedo" (editorial).

${ }^{76}$ Cfr. El Alcázar, 10-VII-1976, p. 1; ABC, 10-VII-1976, p. 1. ABC, sin embargo, también reprodujo en un subtítulo las palabras del Rey que se referían a "hacer posible la participación de todos los ciudadanos".

${ }_{77}$ Cfr. Pueblo, 10-VII-1976, p. 4: "Consultad a todos"; Ya, 10-VII-1976, p. 5: "Haced posible la participación de todos en la determinación de nuestro futuro político"; Informaciones, 9-VII-1976, p. 1: "Haced posible la participación de todos los ciudadanos”; El País, 10-VII-1976, p. 7: “'Haced posible la participación de todos los ciudadanos en la determinación de nuestro futuro', dijo el Rey al Gabinete”; La Vanguardia, 10-VII-1976, p. 3: “Necesitáis hacer un esfuerzo para conciliar la necesaria evolución hacia nuevas estructuras sociales y políticas con el respeto a los valores esenciales de nuestra nación"”; Mundo Diario, 10-VII-1976, p. 1: "Pienso en todos, sin exclusiones"; Avui, 10-VII-1976, p. 10: "Polsar i coèixer profundament les aspiracions del poble"; $E l$ Correo Español, 10-VII-1976, p. 1: “Juan Carlos I: 'Quiero decir a todos los españoles [...] que el Rey piensa en ellos””; Diario de Navarra, 10-VII-1976, p. 1: "A las tareas normales de gobierno se suman hoy las de pulsar y conocer en profundidad las aspiraciones del pueblo español". 
Si bien el nombramiento fue una de las decisiones de Juan Carlos I que más críticas recibió de la prensa durante la transición -un momento histórico en el que la prensa ofreció su colaboración al joven Monarca sobre la base del objetivo compartido de la democratización (Cfr. Zugasti, 2004)-, no debe afirmarse, generalizando, que la reacción de la prensa fue muy adversa. Los periódicos ofrecieron un margen de confianza al nuevo Gobierno y se encargaron de recordarle que su objetivo prioritario era la consecución de la democracia y de las libertades públicas, la meta establecida por el Rey, como también se encargaron de destacar.

De lo anterior deriva el papel jugado por la prensa española durante la transición, actuando a favor de la democratización e indicando bien a las claras el camino que el Monarca y el Gobierno Suárez debían seguir. Evidentemente, es posible encontrar matices entre las distintas cabeceras: así, por ejemplo, Pueblo hizo gala de su carácter gubernamental, El Alcázar mostró que la democracia inorgánica no era plato de su gusto, o el nuevo diario El País apareció como el más beligerante contra la designación por entender que peligraba un tránsito rápido hacia una democracia verdadera.

Respecto al Rey, destaca la potenciación que en las páginas de los rotativos encontró su figura como actor político. Fue dibujado como una personalidad clave, por su poder, en el mantenimiento del rumbo hacia la democracia. Y uno de esos actos decisivos por él protagonizados fue la elección de Suárez -el verdadero primer Gobierno de la Monarquía como insistentemente resaltó la prensa-, a quien quedó estrechamente vinculado a partir de aquel momento.

\section{Referencias bibliográficas}

- Abella, C. (1997): Adolfo Suárez, Madrid: Espasa Calpe.

- Alférez, A. (1986): Cuarto poder en España. La prensa desde la Ley Fraga 1966, Madrid: Editorial Mezquita.

- Areilza, J. M. (1983): Cuadernos de la Transición, Barcelona: Planeta.

- Bardavío, J. (1978): El dilema. Un pequeño caudillo o un gran Rey, Madrid: Strips.

- Barrera, C. (1995): Sin Mordaza. Veinte años de prensa en democracia, Madrid: temas de Hoy.

- Barrera, C.; Zugasti, R., (2001): "La introducción de los valores democráticos en la prensa de la transición española (1975-1978)”, en Benavides Delgado, J.; Fernández Blanco, E. (eds.): Valores y medios de comunicación. De la innovación mediática a la creación cultural, Madrid: Edipo.

- Ferrando Badía, J. (1975): Teoría de la instauración monárquica en España, Madrid: Instituto de Estudios Políticos.

- Fraga, M. (1987): En busca del tiempo servido, Barcelona: Planeta. 
- Instituto de la Opinión Pública (1976): "Encuestas e investigaciones del Instituto de la Opinión Pública”, Revista Española de la Opinión Pública, núm. 44, pp. 283-299.

- López Pintor, R. (1982): La opinión pública española del franquismo a la democracia, Madrid: CIS.

- Osorio, A. (2000): De orilla a orilla, Barcelona: Plaza \& Janés.

- Palacio Atard, V. (1988): Juan Carlos I y el advenimiento de la democracia, Madrid: Real Academia de la Historia.

- Powell, Ch. (1990): “The 'Tácito' Group and the Transition to Democracy, 1973-1977”, en Lannon, F.; Preston, P. (eds.): Elites and Power in Twentieth-Century Spain. Essays in Honour of Sir Raymond Carr, Oxford: Clarendon Press, pp. 249-268.

- Powell, Ch. (1991): El piloto del cambio. El rey, la Monarquía y la transición a la democracia, Barcelona: Planeta.

- Preston, P. (2003): Juan Carlos. El Rey de un pueblo. Barcelona: Plaza \& Janés.

- Tusell, J., y Queipo de Llano, G. (2003): Carlos Arias Navarro entre el franquismo y la Transición (19731976). Barcelona: Crítica.

- Vilallonga, J. L. (1993): El Rey. Conversaciones con D. Juan Carlos I de España, Barcelona: Plaza \& Janés.

- Zugasti, R. (2004): Monarquía, prensa y democracia en la transición española: una relación de complicidad (1975-1978), Universidad de Navarra: tesis doctoral. 